\title{
Investigación y docencia en salud mental (I) Reflexiones para el clínico antes de la autoinmolación*
}

RESUMEN: Se resumen algunos rasgos de la conyuntura ideológica, social e institucional de la investigación, la formación y la docencia en salud mental y el efecto que ciertos de ellos están poseyendo de desmovilizar a los clínicos y provocar «burn-out» 0 «desengaño» de los mismos. Se especifican algunos de los escandalosos déficits formativos de los nuevos profesionales de las técnicas de «salud mental»: en entrevista clínica, técnicas psicológicas, técnicas mixtas, técnicas adaptadas a la red y condiciones autóctonas...

En cuanto a la investigación, se describen el efecto Utah y los afer Darsee y Burt con el fin de efectuar algunas reflexiones sobre sy fundamentación metodológica y epistemológica y sobre sus repercusiones pragmáticas. Por último, se propone una tipología irónica de las pespectivas dogmáticas de la investigación y la docencia en salud mental: la «perspectiva Bambi» y la «perspectiva Godzilla».

PALABRAS CLAVE: Investigación. Formación Continuada. Docencia. Salud mental. Psicopatología. Psiquiatría. Cultura. Coyuntura social.

1. Introducción: situándonos en la coyuntura social e institucional.

El objetivo de este trabajo es proponer una reflexión sobre la situación de
SUMMARY: Paper resumes some issues of social, ideological and institutional context for teaching and researching in mental health as well as its effects on clinic's hope and implicit pressures to "burn-out". Some new-mental health professional's scandalous training deficits are specified: on clinical interview, psychological techniques, shared techniques, technical adaptations to health network and autochthonous context...

On research issues, the author remembers the Utah effect and Darsee and Burt's affairs with the aim to illustrate methodological, epistemological and pragmatic shunts. To end, a ironic typology is proposed for the dogmatic points of view on mental health research and teaching: Bambi's perspective and Godzilla's perspective.

KEY WORDS: Research. Continuous Training. Teaching. Mental Health. Professional burnout. Psychopathology. Psychiatry. Culture. Social Context.

la investigación y la docencia en temas de salud mental en nuestro país. Pero no una reflexión descontextualizada y general, sino una reflexión vinculada a las prácticas clínicas y asistenciales cotidianas en

* Texto reformado de la conferencia de inauguración de las Décimas Jornadas de la Asociación Madrileña de Salud Mental (A.E.N.) Madrid, 11 y 12 de junio de 1998

Rev. Asoc. Esp. Neuropsiq., 2001, vol XXI, n. ${ }^{\circ} 77$, pp. 69-96 
esta coyuntura social y una reflexión, vinculada, además y ante todo, a la situación de las redes asistenciales públicas en salud mental.

No es fácil definir la tal coyuntura social, pues, más que nunca, encontramos opiniones y enjuiciamientos múltiples de la misma. Por ejemplo, hay quien opina que, en nuestro país, la situación presupuestaria en el ámbito de la salud mental comunitaria es de un «reajusta a la baja» o hacia la disminución relativa de los presupuestos. Pero tal perspectiva de la situación presupuestaria es contestada por diversos gestores sanitarios de diversas autonomías, como por ejemplo la de Madrid ${ }^{1}$. Probablemente lo que ocurre es una situación compleja en la que, si bien en varias autonomías el crecimiento de los presupuestos para salud mental se ha detenido, o incluso está disminuyendo, en otras puede que aún continúe, si bien enlentecido, el período de aumento relativo de los mismos. Por otra parte, el tema de la relatividad no es enfocado de la misma forma: no hay uniformidad de criterios entre los responsables de la sanidad de las diversas autonomías acerca de si dichos presupuestos, dado su atraso histórico, deberían crecer más rápidamente que los presupuestos sanitarios generales. Dentro de los diversos capítulos de esos presupuestos, tampoco existe una uniformidad de criterios acerca del reparto de dichos fondos entre los dispositivos hospitalarios o comunitarios de atención a la salud mental.

A esta situación ciertamente no cla$\mathrm{ra}$, sino multiforme, se le está añadiendo una realidad también compleja y multiforme: a diversos niveles, lugares, coherencia y profundidad, se van proponiendo y realizando cambios en el «modelo» de la reforma de la asistencia. Entrècomillo el término modelo porque creo que ya a menudo la situación de partida era de inexistencia o inoperancia de tal modelo. Un «modelo», por cierto, tampoco claro y coherente a varios niveles, pero que ha servido para que hasta los últimos noventa se realizara una importante trasformación de la orientación y dispositivos de la asistencia psiquiátrica -algo muy lejano aún de la «salud mental comunitaria»-en numerosas comunidades. Sin embargo, cabe lo anterior, lo indudable es que, a menudo sin haber explicitado o puesto en práctica el modelo de trasformación de cada comunidad o uno general, se van proponiendo o realizando cambios en ese supuesto modelo, o propuestas de un «nuevo modelo».

Es el caso, por ejemplo, del tan citado y comentado «modelo catalán» de asistencia sanitaria y de sus concreciones en el campo de la «asistencia psiquiátrica y salud mental» -que es como ahora tiende a mencionarse el tal submodelo «psiquiátrico». Pero es que del «modelo catalán de sanidad» creo que lo primero que hay que decir es que no es un modelo de asistencia sanitaria. Nunca lo quiso ser. Como mucho, es un modelo de gestión para combinar intereses e instituciones públicas y privadas, no lo olvidemos. De esa forma, del tal modelo hoy hay que recordar: que, como mucho, es un modelo de gestión; que modelo no significa lo mismo que modélico; que su origen y fundamentos no son precisamente catalanes, pues plantean una determinada línea para la gestión de la sanidad, más parecida a la de los USA que en el anterior modelo español o en varios europeos. 
DEBATES

A estos cuatro datos introductorios de coyuntura institucional y económica, habríamos de añadirle la irrupción masiva de la ideología dominante de nuestro momento histórico. Elementos de tal ideología que quiero destacar aquí son los siguientes: 1. Lo que he llamado la «mentalidad primitiva del (y acerca del) Estado». 2. El «sobrevivencialismo». 3. El confusionismo ante los «hechos diferenciales», utilizados más como bandera para uniformizar o para des-integrar que como marcadores de individualidades y autonomías. 4. La re-entronización del «dios mercado». 5. Su consecuencia directa: el «pensamiento único» con base socio-económica librecambista, anti-protección social. Una manifestación de esa irrupción del pensamiento único, librecambista y seudoliberal, en nuestras instituciones y nuestras prácticas, pueden observarse en la imposición/adoración del biologismo más extremo en sus diversas variantes, fundamentalmente farmacológicas, y la creciente importancia que la industria químico-farmacéutica está atribuyéndose, con la colaboración de los poderes políticos y fácticos, en la formación del personal en salud mental, en las organizaciones y repartos presupuestarios en nuestro campo... e incluso en las diversiones y formas de vida de nuestros profesionales.

Parece bastante evidente que esa nueva ideología y esas relaciones renovadas de producción e intercambio están llegando a nuestras instituciones, como microestructuras sociales que son. Y creo que cada día vamos a resultar más afectados por esa nueva política social, fundamentada en los mismos rasgos ideológicos generales que antes nombraba: el «pen- samiento único». A mi entender, en nuestro ámbito la tendencia al pensamiento único se apoya en una repetición y en un aumento solapado de dos deformaciones ideológicas. La primera, la que llamo, siguiendo a D. Bell (1), la mentalidad primitiva (acerca) del Estado - es decir, del Estado y acerca del Estado- No es mi intención tratar aquí esa regresión mental e institucional que implica el volver a pensar y articular los diversos aparatos del Estado prescindiendo lo más posible de los componentes protectores y organizadores de la sociedad que incluye, y dejándolo cada vez más descarnadamente dedicado a la tarea fundamental de todos los estados: la preservación del orden y los privelegios establecidos. La segunda perspectiva ideológica sí deseaba tratarla, si bien rápida y superficialmente: me refiero a la rampante y a veces casi pornográfica exhibición (por parte de los poderes políticos y fácticos, no de la población) de supuestas perspectivas «científicas» 0 «de interés general» que confirman siempre la necesidad de aumentar la insolidaridad para con los más necesitados, para con los «sumergidos» en el nuevo mundo emergente del librecambismo renovado. El sobrevivencialismo, la ideología que prima ante todo a los esforzados urbanitas que son capaces de sobrevivir a pesar de todos los factores de riesgo y situaciones sociales desfavorables, gracias al empuje de su «fuerza mental e individual» - y a la de la familia y otras sacrosantas instituciones sociales-, se va constituyendo en coartada para todo tipo de recortes en las prestaciones sociales, sanitarias, pedagógicas públicas... Todo queda en manos de la iniciativa privada, cada vez más voraz e insolidaria, sin que se demuestre por otra 
parte su famosa eficacia: al decir de algunos, la enorme diferencia de eficacia y eficiencia entre las empresas públicas y privadas debería servir para que el modelo de la organización privada fuera ya idolatrado por todos los gestores de los servicios comunitarios públicos ${ }^{2}$. Lo que hay que fomentar es esa actitud de «lucha de todos contra todos» y no los servicios y prestaciones sociales, los cuales, desde esa ideología «favorecerían la dependencia y la falta de iniciativa de los más desfavorecidos».

En la medida en la que, como decía, esa ideología, unida a dificultades presupuestarias, está llegando a nuestras instituciones y dispositivos, parece que los clínicos, los que estamos al lado de los consultantes ${ }^{3}$, los que intentamos desarrollar una perspectiva globalizada de los mismos, tenemos pocas cosas que decir. $\mathrm{O}$ mejor que no digamos ninguna y vayamos desapareciendo poco a poco de la escena. Un elemento implícito pero cada vez más visible en esa ideología dominante antedicha consiste en la devaluación de los intentos de globalizar a los pacientes o consultantes, de integrar sus sufrimientos mentales en el conjunto de su personalidad y su medio. Lo «realmente útil» (¿para qué?, ¿para quién?) es la aplicación masiva e ilimitada (en cuanto a población y en cuanto a duración) de psicofármacos que se prometen como pócimas mágicas, que cada vez «curan más enfermedades» y ya no tienen ningún efecto secundario, molestia o peligro... Vamos: el «soma» de Huxley o «el bálsamo de Fierabrás» de nuestro Cervantes. La ideología -que no la evidencia científica - subyacente va convenciendo a más y más gestores, polí- ticos y profesionales: el «mundo ideal» es aquél en el cual cada profesional realiza definidos y eficacísimos tratamientos, científicamente santificados, sobre consultantes anónimos, pasivos y parcializados, los cuales, desde luego, tienen que mejorar. Y así, uno le da psicofármacos; el otro, tal vez, algún modelo de terapia breve o ultrabreve; la trabajadora social le convence de que no hay medios o servicios más allá; el médico, de que debe ir al equipo de salud mental; el equipo de salud mental, de que debe volver a su médico de familia; y, «si la cosa se lía», el «managed care» o un sistema similar instaurará la figura del «manageadon». Y el «manageador» no es que globalice al paciente — para ese viaje no se necesitan alforjas tan costosas- sino que «manageará» los servicios y «tratamientos» que ese ser humano necesita. Se dice que eso resulta más eficaz y eficiente... pero no vale la pena asegurarse mucho sobre el tema, pues lo importante es su hálito de eficacia y eficiencia tecnocrática, gestionarista, americaniza-dora, más que la realidad. ${ }^{4}$

Creo que esos cambios progresivamente acelerados en la política social dominante y en la política económico-social y de los servicios sociales, pueden estar trayendo, entre otras consecuencias, la de que los clínicos, los que intentamos cuidar a los pacientes-personas como sujetos, nos estemos quedando bastante sin la palabra. Es visible hoy una fuerte tendencia a automarginarnos, añadida ahora a la presión marginadora externa y a una cierta tendencia a la autoinmolación basada en la desesperanza y la desconfianza: desconfianza en nuestras posturas, aproximacio- 
nes, conocimientos, que se han demostrado parciales, incompletos, dogmáticos, poco eficaces y eficientes... Desesperanza por cuanto sentimos que no podemos evolucionar, o evolucionar con suficiente rapidez, ante la ola del «pensamiento único», y que es mejor «adaptarnos» que seguir resistiendo, investigando y trabajando en programas de investigación, formación y asistencia más complejos y globalizadores: si lo hacemos, seremos acusados de ineficaces, ineficientes, ideológicos, ilusorios, etc (tabla 1). Ciertamente, en muchos campos nuestros conocimientos y técnicas se han mostrado susceptibles de un cambio urgente y necesario. Pero ¿debemos autoinmolarnos para dar paso a toda una generación de brillantes gestores, brillantes científicos, «investigadores de bata blanca sin veleidades clínicas ni humanísticas»? ¿Tenemos algo que decir ante su «irresistible empuje»? ¿Hemos de resignarnos a evitar el «más dura será la caída» (nuestra) si nos resistimos? ¿Debemos ceder nuestro pensamiento $\mathrm{y}$ nuestros puestos de trabajo $\mathrm{y}$ actividades ante estos «clínicos sin clínica» disfrazados de «científicos» e «investigadores» y ante la cohorte de gestores, economistas, administradores que les arropan, unidos todos en el santo ideario común de la fe ciega en la biología y en la genética? ¿Debemos autoinmolarnos o dejarnos marginar, o aun existen motivos por ejemplo para defender una aproximación a las disciplinas de la salud mental más holística, que siga teniendo en cuenta lo psicológico, $y$, tal vez, lo bio-psico-social?

Mi impresión es que esas repercusiones no hacen sino reflejar, a nivel de nuestras instituciones sanitarias, el siste- mático «acoso y derribo» del «estado del bienestar» y de la ideología que lo sustentaba. Y ello a pesar de que, entre nosotros, en nuestro país, hablar de la «reforma del Estado del Bienestar» es mucho hablar: ese artilugio decimonóninico, causa de tantos sufrimientos, ineficiencias y alteraciones del mercado (si hacemos caso a las voces que claman contra él), la verdad es que sólo muy parcialmente llegó a implantarse entre nosotros, por lo que hablar de su reforma a menudo es contribuir al juego malabarista de las palabras. Además, hay un «pequeño problema»: la población se acostumbró a no valorar los «daños» que el incipiente estado de bienestar le producía $y$, ante cada nuevo recorte, se queja. ¡Pura ignorancia, claro! Pero en el caso de la sanidad se quejan ante nosotros. Y en el caso de la atención a la salud mental, la demanda ha crecido en cuanto la oferta se ha hecho algo menos tercermundista, en cuanto ha salido de la estrechez de las tapias de manicomio y de las consultas de la «neuropsiquiatría de zona» no reformada: de manera que ahora, con la demanda aún creciendo de forma imparable ${ }^{5}$, los consultantes se encuentran, al menos en algunas autonomías, con que se les restringen las visitas, las horas de personal, los tratamientos psicológicos, las ayudas psicosociales... Y por mera transferencia institucional, muchos de ellos viven que somos nosotros los que les negamos y escatimamos esos medios... Con lo cual, los conflictos aumentan, el malestar aumenta... incluso en los lugares y dispositivos en los que aumentan los medios y presupuestos: la demanda crece más rápidamente. $\mathrm{Y}$, sobre todo, la demanda de mayor calidad. No sólo de cantidad, sino también de calidad. 
Esa situación no hace sino aumentar las ansiedades persecutorias y confusionales de nuestros profesionales en el trabajo: aumenta nuestros sufrimientos y nuestra tendencia a la cronificación. De ahí el creciente interés por los estudios acerca del burn-out o, como prefiero decir, el desengaño profesional [(cfr. por ej. Mingote $(2,3)]$. Si los profesionales de orientación psicológica o integradora (de lo bio-psico-social) somos «los ineficaces e ineficientes» $y$, si encima, tenemos que soportar las quejas -precisamente nosotros, porque ante otros la población tal vez siente que no vale la pena quejarse-, de ahí la repetición de mi pregunta: ¿tenemos motivos para no autoinmolarnos? ¿No sería mejor «dejarnos arrastrar por la corriente»? Resistir, oponernos, levantar la palabra y la polémica ¿no servirá tan sólo para que nos quemen o tuesten por otro lado, «por una pura cuestión de simetría», como decía nuestro compañero Luis Martín Santos en otro Tiempo de silencio? En definitiva, ¿es que los clínicos, el pensamiento clínico en salud mental, sigue siendo necesario?

Quería recordarles, además, que las reflexiones que siguen no las voy a hacer desde la perspectiva estrictamente psicoanalítica: para el programa de investigación psicoanalítico la aproximación clínica es central e insustituíble, como he intentado exponer en otros lugares $(4,5)$. Partir de él para defender la necesidad de lo clínico tendría pues demasiado de tautología. Por eso, cuando realizo estas reflexiones procuro consultar previamente autores de otros marcos de referencia: en particular, para ver qué dicen, en qué estimulan mi pensamiento, qué me sugieren.
Como en mis trabajos sobre psicoanálisis y cognitivismo o en las anteriores revisiones sobre la calidad como terapias de las psicoterapias $(6,10)$. Porque, a pesar de todo, hemos de partir de que ni el pensamiento clínico ni el psicoanálisis deben posicionarse en contra de racionalizar la asistencia en salud mental, de la investigación empírica e incluso experimental, de los intentos e investigaciones para hacer más eficaces y eficientes nuestras técnicas, del control de nuestros servicios por parte de las organizaciones públicas, administrativas y políticas, etc.

2. La coyuntura en formación y docencia en el ámbito de la psicopatología y la salud mental.

Es absolutamente cierto que nuestras aproximaciones clínicas pecan hoy de ineficacia, ineficiencia, falta de seguridad, oportunidad, accesibilidad, etc (tabla 1). Al menos, si comparamos los progresos de la psiquiatría y la psicoterapia con los de otras ramas de las ciencias médicas y sociales. Pero ¿qué ocurre con la formación de nuestros médicos, psiquiatras y psicólogos, tras varias décadas de desprecio universitario por el pensamiento y la aproximación clínica en psicología y psiquiatría, tras dos decenios de desprecio por las teorizaciones dimensionales y clínicas a favor de las teorizaciones categoriales y supuestamente «ateoréticas» o declaradamente conductistas?

En primer lugar, los que nos dedicamos al menos parcialmente a la formación y la docencia comprobamos que, con esas profesiones, incluso con los psicólogos, necesitamos hacer cada día más y más formación continuada elemental por défi- 
cits de pregrado escandalosos. Por ejemplo, las técnicas de entrevista y el entrenamiento y la tutorización o supervisión para las entrevistas son descuidados en gran parte de los programas de especialización - y no digamos en la formación pregrado de medicina. Pero también en los progamas postgrado de psiquiatría y psicología clínica.

Otro ejemplo más pormenorizado: sólo en años recientes ha comenzado a formarse a los especialistas en medicina de familia y comunidad (MF y C) en... psicosociología de la familia, técnicas de entrevista familiar, técnicas grupales y psicosociales, etc. Y, desde mi punto de vista, todos esos ámbitos, básicos para el trabajo de los «médicos de familia y comunidad», no son ni de lejos adecuadamente enseñados, supervisados, tutorizados hoy en nuestro país... Como ocurre con la formación para la entrevista clínica, una herramienta básica en el trabajo del médico, del psiquiatra, del psicólogo y, en general, de cualquier profesional asistencial ${ }^{6}$.

En segundo lugar, en la docencia médica, postgrado y pregrado, de especialistas en MF y C, en psiquiatría o en medicina interna, se prima, ante todo y sobre todo, lo biológico. Para lo demás se piensa más o menos implícitamente que siempre habrá tiempo y presupuestos.

En tercer lugar, se esta tendiendo a primar cada vez más «el maravilloso curso que en muy pocas sesiones y en muy poco tiempo va a proporcionar conocimientos, habilidades y felicidad a muchísimos clínicos, maravillosa y rápidamen- te». Es decir se prima lo sincrónico y puntual: porque es más barato y porque no obliga al compromiso - y a compromisos en el «peligroso capítulo 1»: el capítulo del personal一. Así, cualquier enseñanza o proceso formativo diacrónico es desechado para evitar el compromiso con presupuestos diacrónicos y sujetos siempre a restricciones o a caprichosos cambios estacionales.

En cuarto lugar, tiende a primarse o bien lo teórico y retórico o bien los sistemas que impliquen maquinización -que no es lo mismo que tecnificación: las técnicas psicosociales son también técnicas y tecnologías, aunque no utilicen máquinas en muchos momentos.

Y todo eso, en sexto lugar, no coincide con là marcha de la economía, que pasa, al parecer, por una época de bonanza en nuestro país. Lo que significa que las restricciones que padecemos en la asistencia pública, mayores si cabe en la atención en salud mental y psiquiatría - y mayores aún en la formación en estos ámbitos-, no son económicas sino políticas. $\mathrm{Y}$ no las aplican solo «los políticos de arriba» sino los gestores de bastante más abajo. Parafraseando una frase muy conocida «Si España va bien, ¿cómo es que los cuidados a la salud mental comunitaria no van, ni de lejos, $\tan$ bien?»

Y por último, en séptimo lugar, cuando se habla de que el sistema público no puede costear muchos de esos procesos formativos, que sin embargo se creen necesarios e imprescindibles, y que hay que buscar financiadores, «esponsors» externos $i^{\text {no }}$ se está disociando la realidad de que el cos- 
te de muchos de esos congresos, simposios, jornadas, etc financiados a todo lujo sale también de las arcas públicas, por ejemplo a través del capítulo de farmacia de nuestros presupuestos, siempre creciente?

Como muestra de la situación les quería describir el ejemplo del grupo de trabajo, convocado por el Servei Catala de la Salud, sobre el tema de la formación continuada en salud mental para la APS. Fué un grupo de trabajo interdisciplinario, interparadigmático, intersectorial, interempresarial, con representantes de todos los estamentos profesionales, gerenciales y administrativos de la sanidad catalana, con representantes de la empresa pública (el ICS) y de las empresas privadas concertadas, de la APS y de las redes de SM, etc. Un grupo realmente integrador, en el cual logramos ponernos de acuerdo - y no fué difícil, dadas las enormes carencias de las cuales partimos- para definir los ámbitos prioritarios que debería cubrir la formación continuada en SM para la APS. ¿Cuáles eran esos ámbitos formativos que definimos como prioritarios para los próximos diez años? Los que vienen señalados en la tabla 2: formación para la entrevista clínica, un curso básico de introducción a la salud mental comunitaria, temas diferenciados por cada una de las profesiones que forman la atención primaria, programas preventivos, atención primaria al duelo y las pérdidas, curas y técnicas de enfermería especializadas, técnicas grupales para los trabajadores sociales de atención primaria... Y además, el grupo de trabajo estaba de acuerdo, sin problemas de discusión especiales, a pesar de la diversidad de composición y procedencia, en destacar los «grupos Balint» o equivalentes, por ejemplo los grupos tipo PBI cognitivistas $(11,14)$, como un elemento básico para la formación en salud mental de los profesionales de atención primaria en los años futuros.

Como les decía, se trataba de un grupo interprofesional e interempresarial, tutelado pero no manejado por la aministración... Es decir, un grupo que tenía ciertas posibilidades de que sus recomendaciones fueran llevadas adelante, se convirtieran en realidades. Y, tras un renqueante principio, así ha sido... menos en uno de los casos ¿Imaginan cuál de todas esas actividades formativas no se está realizando, dos años después de haber puesto en marcha el sistema?. No resulta difícil intuir que son precisamente los grupos o «seminarios de reflexión». A pesar de que, precisamente, se trata de uno de los sistemas formativos en salud mental más estudiados y validados, incluso desde el punto de vista empírico (cfr. un resumen del tema en $(11,14)$. Es cierto que enfrentan dificultades $y$, entre ellas, que hoy por hoy existen pocos profesionales formados para coordinar tales grupos. Pero sobre todo, tienen en su contra que son una formación diacrónica, que necesita, por tanto, presupuestos diacrónicos y que no prometen maravillas a corto plazo a nadie: dos grandes inconvenientes para que la administración sanitaria financie dichos seminarios de formación continuada, mientras que puede estar financiado mil y un cursos y «cursetes» sobre temas variopintos, marginales en ocasiones... pero con promesas de resultados inmediatos y marvillosos, desde luego.

Tras esas reflexiones sobre la coyuntura de la formación en salud mental, 
DEBATES

querría dar ahora al menos cuatro pinceladas generales para situar la investigación en este contexto.

De entrada, simplemente recordaría cómo, en el momento actual, se están primando investigaciones a corto plazo que producen «importantes descubrimientos»... que luego no son usados en las técnicas ni en las prácticas de los equipos de salud mental (a menos que esas investigaciones sean fundamentalmente biológicas, se refieran a la difusión o comercialización de fármacos producidos por las empresas trasnacionles del sector). Por otra parte, ante muchas de tales investigaciones deberíamos seriamente preguntarnos qué parte tienen de investigación en salud mental o psiquiatría y qué parte tienen de investigación en mercadotecnia. Las investigaciones de marketing y merchandising son investigaciones que en nuestro modelo de sociedad no resultan, ni mucho menos, ilegales o deshonestas... Pero no son investigaciones en salud mental.

Otras investigaciones, cada vez más frecuentes, tratan directamente de apuntalar al propio equipo investigador. Es el fenómeno o efecto Utah, del cual hablaré en este trabajo en más de un momento. Se trata de un fenomeno del que se viene hablando en epistemología y en teoría social de la ciencia al menos desde los años ochenta, tras los trabajos de Pool (15).

El efecto Utah tomó su nombre de la Universidad de Utah: en el año 1972, en esa universidad, John Kepros realizó el anuncio de que se había descubierto un láser mediante rayos $X$. Desde luego, ello supondría un especta- cular avance para la ciencia física y para la tecnología: se podría prescindir de otros tipos de láser más habituales y que necesitan consumos energéticos mucho más altos. El funcionamiento del láser se había demostrado mediante impresiones fotográficas. Siguió un un gran revuelo de los medios de difusión científicos y no científicos, al parecer bastante bien orquestado. La polémica, como resultado más o menos directo, proporcionó una buena cantidad de llamadas para confrencias, becas, cursos y ayudas para la investigación al equipo liderado por Kepros. Pero en muy pocos meses se demostró que las famosas impresiones en las placas fotograficas habían sido producidas... por los propios rayos $X$. Es decir, el láser por rayos $X$ todavía no existe. Sin embargo, para cuando el fraude o la equivocación se descubrio, el equipo investigador tenía cubiertos sus presupuestos para 5 años. He ahí el resultado de una adecuada mercadotecnia sobre determinado tipo de investigaciones $y$ descubrimientos científicos y tecnológicos. Creo que deberíamos reflexionar más a menudo sobre el peso del «efecto Utah» en la investigación contemporánea. Al menos, en nuestros ámbitos psiquiátricos, donde me parece que hoy está jugando un papel relativamente importante en la encrucijada técnica, asistencial y formativa de la psiquiatría y las especialidades de la salud mental actuales.

En otro orden de cosas, pero dentro del ámbito de la investigación en salud mental, ¿cuantas veces están mínimamente adaptadas las técnicas que se aplican y se 
investigan? ¿Hasta qué extremo están contextualizadas, es decir, poseen una adecuación, continuadad, efectividad (o «eficacia en condiciones reales»), oportunidad, seguridad, etc.(tabla 1), estudiada en nuestras coyuntura social y no en los U.S.A.? $O$, ¿es que no interesa que lo estén, porque interesa uniformizar?

Probablemente, el coste de los nuevos psicofármacos, si se administraran, como se propone en los programas y recomendaciones biologistas, al 1 a 3\% de la población, arruinarían a los sistemas de Salud, al menos al sistema de salud español. Por ejemplo, como muestra la tabla 3 (16, 18), durante 1996 el consumo DDH de los antidepresivos en Cataluña, creció en el $48 \%$ con unas variaciones interprovinciales absolutamente inexplicables desde el punto de vista de la salud mental y epidemiológico-psiquiátrica: desde 12 dosis/ mil habitantes/día en Tarragona hasta 20 dosis/ mil habitantes/día en Girona ¿Como pueden producirse esos datos? $\mathrm{Si}$ se le añade el consumo de benzodiacepinas, que en Cataluña ascendía ya ese año por $44,29 \mathrm{dosis} / \mathrm{mil}$ habitantes/día (80 DDH en realidad, si se tiene en cuenta el consumo no regular, no recetado por el SCS), y también con otras llamativas diferencias interprovinciales, tenemos la realidad de que probablmente estarán usando psicofármacos de forma crónica en Cataluña entre 1 de cada 11 y 1 de cada 12 catalanes en este momento. ¿Y qué decir del consumo del metilfenidato, que parece ser que habría que administrar durante años a todo supuesto niño «hiperactivo», haciéndole realmente drogodependiente, sin datos empíricos que sustenten tal uso en investigaciones a cinco años y de enfoque biopsicosocial? Pues no se sabe claramente cuánto está aumentando su recpetación, pero un dato indirecto es escalofriante: en USA, en seis años (1990-1997) aumentó en el $500 \%$, en Alemania, entre 1990 y 1994, en el $300 \%$... Esa progresión parece de todo punto disparatada y está dando lugar cada día a más problemas clínicos y asistenciales. Pero es que en España somos más rápidos: en un sólo año (19961997)... jaumentó dicha fabricación en el $484 \%$ !. Claro está que tal vez se use como abono para que las plantas crezcan más felices...

$Y$ aquí, en el campo de la investigación y consumo farmacológico hay una diferencia notable con respecto al ámbito de la docencia: con la excepción de algunas facultades de Psicología, el predominio de la investigación biológica, el predominio en la investigación estrictamente biológica y a veces biologista, es abrumador. Y son investigaciones muy parecidas entre sí, a menudo «multicéntricas», con metodología similar, realizadas al mismo tiempo sobre psicofármcos iguales o diferentes... Son investigaciones que suelen ser publicadas posteriormente en «revistas de impacto internacionales» y que proporcionan importantes beneficios de todo tipo (sobre todo, académicos) a los equipos investigadores: es una manfiestación descollante de lo que ha dado en llamarse el efecto Darsee, fenómeno que vale la pena recordar aquí (19).

John Darsee era un investigador en cardiología clínica y experimental de la Universidad de Harvard. A raíz de un típico concurso universitario, tuvo que reconocer que habia falseado unos datos de un estudio publicado en una 
revista de primer orden internacional; que, por lo tanto, había engañado al comité de selección con datos abiertamente falsos. Eso puso en marcha toda una serie de comités científicos, de ética y de la redacción de las principales revistas de la especialidad de los USA (recuerden que la cardiología clínica y experimental es una especialidad alta relevancia para la vida de los pacientes). Un resultado es que se encontró que en 3 años, del 78 al 81, John Darsee habia publicado 109 trabajos experimentales y empíricos lo que daba una media de un trabajo cada 10 días. Eso significaba, como luego se demostró, que gran parte de los trabajos estaban llenos de fraudes, falacias, mentiras, inventos de datos y demás $y$, sin embargo, gracias a la «autopromoción» (al «efecto Utah») habían penetrado en todas las revistas, no solo de la Universidad de Harvard, sino en las revistas de máximo prestigio internacional de la especialidad. Incluso el New England, una de las revistas más estrictas en cuanto a su selección de originales, puso en marcha todo un comité para juzgar las publicaciones publicadas por John Darsee en su revista.

Al contrario de lo que suele decirse, este tipo de problema no es ocasional, circunstancial o personal: como algunos comités y pesonalidades admitieron a raíz del afer, más tarde repetido en innumerables ocasiones, el asunto apuntaba al «corazón de la publicación científicas y ponía en entredicho los motivos para publicar y la capacidad de las revistas más prestigiosas par evitar la publicación de datos falsos si el «investigadon» conocía bien los mecanismos de publicación y se halla adecuadamente «representado» $y$ «reconocido» (efecto Utah) en el ambiente académico y de las publicaciones.

Mi duda es si son posibles hoy en día planteamientos y políticas muy diferentes de la investigación y la publicación, especialmente en los «países secundarios del Imperio». Porque en la medida en que la investigación se base en los planteamientos y formas de publicación puestas en evidencia por el «afer Darsee», queda facilitado por un lado el derroche presupuestario; por otro lado, el efecto Utah y el efecto Darsee. En consecuencia, la poca eficiencia de la investigación. Y ya que ahora a los clínicos nos están juzgando por la eficiencia, y creo que hemos de estar de acuerdo en que esa valoración se haga aunque de forma menos simplista y sesgada de como se hace, pero esa es otra cuestión - no estaría mal que a los investigadores se les juzgara también por su eficiencia, por los resultados y mejoras que sus investigaciones proporcionan en la tecnología, técnicas y prácticas asistenciales. Ya que las investigaciones en «ciencia básica» no pueden ser muy frecuentes en los países secundarios del Imperio, al menos la eficiencia con respecto a la sociedad que costea esas investigacioens debería ser también un criterio fundamental en las investigaciones tecnológicas, sobre ciencias aplicadas y técnicas terapéuticas.

3. Dos perspectivas de la investigación y la docencia en psiquiatría y demás «disciplinas de la salud mental»

Para situar el conjunto de datos anteriores en nuestra coyuntura sociopolitica, 
científico-técnica e institucional, yo les propondría una reflexión sobre las dos perspectivas, más o menos explícitas y conscientes o más o menos implícitas e inconscientes, con las que se tiende a afrontar la investigación y la docencia en nuestro ámbito. A esas dos perspectivas, un poco humorísticamente, las he llamado «perspectiva Bambi» y «perspectiva Godzillas ${ }^{7}$. Me parece sugerente designar así dos perspectivas de la investigación y docencia en salud mental, tal como son vividas y difundidas en nuestra comunidad técnica: la una, la investigación «fuerte», sobre «ciencias básicas», apabullante, pero con indudables valores y utilidades, diferentes a veces de su aspecto *básico y fuertex. La otra, la respuesta y la oposición en nombre de la «sensibilidad», la «reflexión», la «hermenéutica»... pero que, con cierta frecuencia, singifica un lastimosa inoperancia, una paralización de las ideas e iniciativas por fantasías sadomasoquistas sobre «lo nefastos y monstruosos que son los partidarios»... de la postura anterior. Son las dos posturas que he intentado resumir en la tabla 4.

Según la perspectiva Godzilla, la investigación debe ser una investigación básica, científica, orientada a la biología, reduccionista, casi nunca biopsicosocial, con una metodología muy estricta y con una epistemología que casi siempre es empirista (empirista decimonónica a menudo), con fuertes influencias del solipsismo y el mecanicismo en numerosas ocasiones. Pero a ella se le suele oponer en nuestros medios de salud mental, y en especial en las instituciones extrahospitalarias de salud mental, una perspectiva «Bambi». Es la que tradicio- nalmente defienden psicoanalistas, psicodinamistas, humanistas, algunos sistémicos, algunos cognitivistas, etc: según esa perspectiva, la investigación no tiene por que ser en ciencias básicas y se subraya la importancia de la «investigación clínica» y de la reflexión sobre la clínica - aunque a veces se confunde reflexión con investigación.

Desde la perspectiva «Bambi» se priman las investigaciones psicologicas particularizadísimas de lo individual o de grupos sin controles $y$, por lo tanto, poco comparables por definición. En pocas ocasiones se plantean investigaciones psicosociales, epidemiol6gicas, sociologicas. Cierto que la perspectiva Godzilla se orienta a menudo hacia una investigación reducionista, casi nunca biopsicosocial, mientras que la perspectiva Bambi tiende a esas investigaciones tan, $\tan$ cualitativas... que, por ejemplo, pocas veces se investigan las terapias que en realidad hacemos: se tiende a sustituir la metodología por la reflexión y a idealizar y aceptar visiones dogmáticas y no operativizadas de los conceptos y técnicas, lo cual invalida a menudo estas supuestas investigaciones. La epistemología de la perspectiva $\mathrm{Bambi}$, sin embargo, suele estár mucho más actualizada: metateóricamente a Bambi le sustenta la hermenéutica o la epistemología constructivista o contruccionista... aunque algunos planteameintos de formación y docencia parecen más basados en la pura «epistemología del sentido común» - y a veces, tan de sentido común que parece dadaista.

Desde la perspectiva pragmática (tabla 5) la postura Godzilla de la investi- 
gación es «imperial» por definición: es la que se hace en el Imperio. El imperio determina qué centros hacen las investigaciones y cuáles son las grandes líneas de investigación que deben ser primadas ( «la década del cerebro» es una buena muestra; el Proyecto del Genoma Humano, otra). Pero la contestación, desde la perspectiva «Bambi», es una especie de confusa propuesta en la que «la buena investigación y la buena docencia» son asuntos de grupos e indivíduos aislados, solitarios, no integrados... La perspectiva Godzilla admite la posibilidad de investigar tanto científica como tecnologicamente, es decir tanto en ciencia como en tecnología; ahí la perspectiva Bambi le contesta a menudo con propuestas que se llaman «investigaciones» y que en realidad tienen mucho que ver con divagaciones, idealizaciones, repeticiones... o con un cierto seguidismo de grandes figuras que se endiosan y que se reproducen bibliofílicamente. La perspectiva Godzilla es una perspectiva que habla de la eficacia y se centra en la eficacia. Erróneamente, a este «funcionalismo» la perspectiva Bambi opone el hincapié en lo humano, en la hermenéutica. La perspectiva Godzilla defiende la investigación y la docencia desde las instituciones psiquiátricas: pero el trasfondo de esta idea es que sólo considera «instituciones» a las instituciones totales, en el sentido de Goofman (20): servicios de psiquiatría hospitalarios, hospitales psiquiátricos, universidad... En contadas ocasiones, si no es utilitaristamente, se tiene en cuenta a los equipos de Salud Mental Comunitarios o las pequeñas instituciones en la comunidad... Pero en esa falta de consideración colaboran abiertamente con frecuencia los partidarios de la uperspectiva
Bambi», que suelen defender, a menudo quijotescamente, que la buena investigación es la propia de las mentes pensantes y sensibles, más allá de la ciencia, más allá de los protocolos...

Es la investigación Godzilla la que se publica en las revistas de prestigio internacional, con más penetración mediática: pero el fenómeno Darsee muestra hasta qué extremo las «revistas de prestigio internacional», y el mismo hecho de publicar, pueden ser pervertidas en sus raíces por intereses espúreos y falseadores. Ante esa situación, la «perspectiva Bambi» se acantona a menudo en un desprecio más que excesivo, autodestructivo, hacia el hecho de publicar en esas revistas y hacia los sistemas, técnicas y medios protocolizados, comunicables, difundibles en procesos formativos sistematidos... Es decir: en último extremo, ante una perspectiva Godzilla (empirista, biologista, metodologista, pero poderosa) se le opone aquéllo de « ¡Cómo hacerle comprender al mundo que lo nuestro es maravillosamente distinto!». A mi entender, es una vía equivocada para contestar a la perspectiva Godzilla. Pero no es la única. Existen otras perspectivas, tal vez menos sectarias, de la investigación y la docencia en salud mental en nuestra coyuntura sociocultural que voy a intentar plantear a continuación.

Es cierto que la investigación dominante es la supuestamente básica, al menos en biología $a^{8}$. Pero hay muchas vías y ámbitos en los que perfectamente se podrían desarrollar líneas de investigación aplicada y pragmática. Es cierto que la investigación más comunicable y verificable es la investigación cientifica; la que, a 
medio plazo, abre más posibilidades y vías para el conocimiento y trasformación de la realidad. Pero eso no elimina el valor de las investigaciones técnicas y tecnológicas, que también siguen la metodología científica. Y no hay que olvidar que, aunque no lo parezca así, la influencia ideológica es básica en la investigación en ciencias básicas: y mayor, cuanto más medios económicos y apoyos necesiten las investigaciones para ponerse en marcha. El afer Burt es una buena muestra de la contaminación de la investigación básica por cuenta de la ideología, como lo es, en nuestros días, el frecuente arrumbamiento de psicofármacos que pocos años (¡o meses!) antes habían sido presentados como fantásticos curalotodos o solucionadores de intrincados y complejos problemas, como ocurrió, sin ir más lejos, en 1998 con un psicofármaco que al año del lanzamiento comercial se mostró involucrado en varias muertes por problemas cardíacos.

Como ustedes saben, Sir Cyril Burt, uno de los fundadores de la Psicología inglesa y maestro de H. Eysenck, fue nombrado Sir por su Majestad Británica en honor a sus aportaciones a la investigación psicológica. Uno de sus temas fundamentales de investigación versaba sobre la heredabilidad del cociente intelectual, tema en el que mantuvo una tenaz y acérrima postura "genetista" (como la de su discípulo H.J. Eysenck, para el cual, cerca del $80 \%$ del CI está genéticamente determinado) $(21,22)$. En su época, además, la demostración de tal «heredabilidad * del CI proporcionaba importantes apoyos "científicos" a la ideología de la derecha, a menudo al racismo y, desde luego, «a un mundo es- table y (casi) perfecto». Naturalmente, para estudiar estos temas debía hacerlo con amplias muestras de gemelos - a ser posible, monocigotos. Logró reunir una amplia muestra de 76 gemelos univitelinos que fueron estudiados mediante amplias baterías psicológicas. Para ello, desde luego, se necesitaba ayuda. Y la obtuvo: todos sus trabajos de esa época están firmados, además de por él mismo, por la Srta J. Conway y la Srta Margareth Howard. Molestos investigadores (2325), han demostrado una y otra vez, a pesar de los ataques personales y descalificaciones de Eysenk y Jensen, que existían todo tipo de falsedades y falacias en los datos aportados por Burt y, en último extremo, que la Srta. Conway y la Srta Howard no solo no eran psicólogos, no estaban inscritas como tales en el Reino Unido, sino que probablmente nunca existieron: es decir, que gran parte de esos datos sobre la herencia del coeficiente intelectual fueron totalmente inventados.

Se trata de una muestra más de que, si bien la investigación científica es necesaria y la fuente más fiable de datos para conocer y trasformar la realidad, también puede resultar penetrada sin embargo por todo tipo de deformaciones ideológicas, errores, autoengaños, falsedades, etc.

Otro dogma similar se resume en el aserto de que la investigación científica es acumulativa y reductora del desconocimiento (tabla 6). Se trata de una idea bastante elemental y simplista desde el punto de vista epistemológico: es cierto que la ciencia disminuye el desconocimiento 
pero, además, con los cambios de perspectiva o paradigma que promueve, reduce y cambia los dogmas, es decir los pseudoconocimientos. La teoría geocéntrica no era un desconocimiento: numerosos datos factuales, empíricos, militaban a su favor. Los fenómenos que parecían favorecer otra postura, por ejemplo la teoría heliocéntrica, pudieron así ser rechazados durante milenios, hasta Copérnico y Galileo, porque podían ser interpretados como simples «anomalías» de la teoría geocéntrica.

Como ustedes saben, en la investigación actual en psiquiatría y salud mental predomina de forma abrumadora la investigación biológica. La investigación biológica durante la segunda mitad del siglo XX ha realizado, además, grandes aportaciones teóricas y técnicas. Pero eso no debería hacernos perder de vista la posibilidad, tal vez más adaptada a nuestros medios, de hacer investigación psicológico-clínica, psicosociológica, psicobio-lógica, asistencial, epidemiológica, sobre técnicas mixtas (incluyendo las biológicas), etc. Por ejemplo, parece que la investigación sociológica sobre las instituciones y la salud (mental) ha desaparecido de nuestras revistas científicas ise tratará tal vez de una «especie sesentaiochesca» en vías de extincion?

Otra tendencia dominante, tanto en la investigación como en la docencia, es el reduccionismo. A menudo, el reduccionismo es tal que parece simple y llanamente mecanicismo $(26,27)$. En otras ocasiones, se trabaja con una reducción implícita de la metodología para la comprobación de hipótesis, con una implícita reducción extrema de la metodología cientí- fica, como si la única metodología posible fuera la metodología estadísticocorrelacional de los estudios clínicos de rigor. Pero hablar del «método científico» ya muestra de entrada un importante reduccionismo. Hemos de recordar que, normalmente, cuando así hablamos, estamos designando nada más los métodos científicos para la comprobación de hipótesis, para el contexto de justificación. Nada decimos entonces de la pluralidad de métodos para el contexto de descubrimiento. En este caso, los métodos se podrían contar por decenas (28). Pero, como digo, tampoco los métodos científicos para la comprobación de hipótesis pueden reducirse a uno sólo, con la hipostasía dogmática subyacente de la metodología experimental. Actualmente ya están suficientemente delimitados y descritos otros métodos científicos para la comprobación de hipótesis: el estadístico-correlacional, el observacional y el experimental -a los cuales, los físicos teóricos y los estudiosos de grandes flujos proponen añadir el método simulativo como un método directamente apoyado en el desarrollo de la informática.

A otro nivel, la base epistemológica de la mayor parte de la investigación y la docencia en salud (mental) es el empirismo: se cree, más o menos implícitamente, que la investigación y la docencia van orientadas hacia y por «la Verdad», «la Realidad», a la cual se llega por la acumulación de datos (empíricos). Pero tal vez fueran mucho más rentables perspectivas ontológicas y epistemológicas emergentistas $\mathrm{y}$, sobre todo, constructivistas y construccionistas: de hecho, entes tales como la «Verdad», con «V» mayúscula, 
son entes muy difíciles de descubrir, sobre todo desde Heissenberg y su principio de indeterminación, y «la realidad» (o los diversos tipos de realidades) se construye en la interacción sujeto-objeto (constructivismo).

A niveles más pragmáticos (tabla 7), el aserto dominante, como decíamos, es el que propone una «división internacional del trabajo de investigación» entre el Imperio y sus Centros Secundarios: las grandes líneas las marca el Imperio y en los Centros Secundarios el papel fundamental consiste en la replicación de experiencias o líneas y papeles secundarios con respecto a las líneas maestras marcadas desde ese Imperio (trasnacional). Pero ipor qué hacerlo así? ¿No tendríamos más posibilidades investigando diferencias, investigando cualidades, investigando en otras tecnologías «blandas», por ejemplo psicosociales, investigando nuevas técnicas $\mathrm{o}$ adaptaciones tecnológicas a nuestras formaciones sociales? No hay que olvidar la realidad de que, si bien de los niveles de eficaciay de productividad de algunos centros asistenciales e investigadores norteamericanos tenemos mucho que aprender, posiblemente no estamos tan por debajo - sino probablemente por encima- del nivel medio de eficiencia del sistema sanitario. Y el nuestro es, además, con sus mùltiples defectos e insuficiencias, mucho más generalizado y equitativo. Ni nos movemos tan por debajo del nivel medio de la institución media investigadora o universitaria norteamericana. Son datos que, no por conocidos, resultan suficientemente tenidos en cuenta en las perspectivas europeas de investigación y docencia: numerosas líneas de investigación y docencia norteamericanas son dudosamente aplicables en nuestras formaciones sociales, con una sanidad pública para toda la población y con una eficiencia que sitúa al sistema sanitario español, con todas sus deficiencias, entre los cinco o seis primeros del mundo, además de uno de los pocos que han podido combinar un cierto desarrollo de la atención primaria con un cierto desarrollo de la salud mental comunitaria pública. Hay mucho que investigar en este sistema particular y mucho en qué ampliar nuestra formación para mantenerlo y mejorar su efectividad y eficacia, sus disfuncionalismos, su equidad...

Y ya que hablamos de investigación de las «cualidades de nuestras técnicas y nuestro sistema», es evidente que habría que desbordar de una vez por todas las simplistas investigaciones sobre la eficacia de fármacos, psicoterapias, tratamientos mixtos, y pasar a estudiar el resto de las «cualidades de una terapia o sistema tecno-sanitario cualquiera» (tabla 1): eficiencia, seguridad, oportunidad, accesibilidad, equidad, calidad de vida a la que contribuye, etc. Y eso puede hacerse en todo tipo de «instituciones sanitarias» y no sólo en las «grandes instituciones» $u$ hospitales.

Probablamente, las necesidades de investigación en uno y otros contextos son bien diferentes: puede ser una razón para relativizar el aserto dominante de que «la investigación es lo que publican las 'Revistas de Prestigio internacional' y los bancos de datos como MEDLINE y similares». Hoy en día existen otras posibilidades de revisión de cualquier tema de investigación probablemente más fiables y seguros: redes paralelas de investigadores, foros infor- 
DEBATES

males, consulta de revisiones y metaanálisis de instituciones independientes como la Colaboración Cochrane, participación en grupos de discusión como los de Internet y similares, consultas directas a grandes centros bibliográficos mundiales, etc.

A nivel de ejemplo, vale la pena recordar aquí una experiencia que es muy común entre todos nosotros. Con fines docentes o de investigación, numerosos investigadores españoles realizan búsquedas, por ejemplo en Medline. En mi caso, yo hago al menos una búsqueda anual de trabajos acerca de la prevención de salud mental. Con las marcadores que utilizo, cada año aparecen preseleccionados unos seis o siete mil trabajos. Tras un cribado general inicial, suelen quedar entre 300 y 500 trabajos que tal vez posean algún interés remoto. Entrando ya en los resúmenes de los trabajos, la siguiente selección los deja en 40 o 50. Y estudiando después esos trabajos, el grupo de expertos sobre el tema de la SEMF y Cencuentra que tienen un cierto interés para nosotros entre 3 y 4 trabajos (desde luego, un máximo de 10). Y eso para un grupo de trabajo dedicado especí-ficamente al tema de Prevención en Salud Mental dentro de la Sociedad de Medicina Española y Comunitaria. Atrás quedan, cada año, centenares y miles de trabajos que en este país yo no sé si se publicarían, pero que, desde luego, muchos no leeríamos. $Y$ seguro que esta experiencia resulta replicada por otros muchos investigadores y estudiosos españoles con ese y otros "bancos de datos» y con algunos productos punteros similares.
Por otra parte, del valor real, de la efectividad (o eficacia real) de la investigación estadístico-correlacional en el mundo actual, dominado por el Dios mercado y el «efecto Utah», da una buena muestra la retirada anual de fármacos para los cuales, unos años antes, se ha postulado todo tipo de excelencias y superioridades. Antes he puesto un ejemplo de un psicofármaco retirado del mercado en 1998 , en un tiempo récord tras su entrada en el mercado: menos de un año. Algo similar deberíamos decir del «tolcapone», otra estrella fugaz de la farmacología contemporánea, en este caso de la galaxia de los antiparkinsonianos... ¿qué ocurre entonces? ¿Que esa metodología científica debe ser reconsiderada, pues deja demasiado abierto el campo a la aleatoriedad, el «efecto Rosenthal»», a la hipótesis nula...? ¿O bien que, hoy por hoy, es imposible en nuestros ámbitos sustraernos al «efecto Utah», como han demostrado bien recientemente el lanzamiento de cierta fluoxetina y la «reconversión» de las indicaciones de algún otro psicofármaco para incluir «la timidez», o, unós años antes, el descubrimento del virus de la inmunodeficiencia humana (VIH), y este mismo año, del «sildenafilo» o «Viagra» ? ${ }^{10}$

Es evidente que, en ocasiones, esos efectos se buscan intencionalmente: ese es el caso por ejemplo de la fusión fría descubierta (en la imaginación) en 1989 por Stanley Pons, un investigadornorteamericano, probablemente de origen catalán, y Martin Fleischmann, un profesor checoeslovaco afincado en Inglaterra... Sería maravilloso que simplemente con la introducción de electrodos de paladio en agua pesada fuera posible convertir el hidrógeno en 
helio, con la gran liberación de energía que ello supone. Si esa transformación se consiguiera, supondría la liberación de los actuales problemas energéticos actuales de la humanidad. Que lástima que esa supuesta "fusión fría» sólo fuera posible realizarla en tres ocasiones: una, Pons y Fleischmann. Pero las primeras venían ya de 1927 y 1929 de tres científicos (¿o habría que decir fabuladores?): un sueco y dos alemanes $(19,29)$ La propia revista «Science» revelaba el artilugio de relaciones e influencias que los investigadores anglosajones habian utilizado para conseguir introducir la noticia ...jen el «Financial Times»! (29) Pero para entonces, plenamente montados en el "efecto Utah», Pons y Fleischmann ya habian conseguido ayudas a la investigación ¿tal vez para unos 10 años?...

Todo lo anterior, si no hubtéramos caído demasiado en una deformación dogmática del ideal y el valor de la ciencia, no debería llevarnos a «rasgarnos las vestiduras». En realidad, no hay que olvidar que toda investigación implica una dialéctica entre el conocimiento como fin en sí mismo cabe el conocer para transformar $y$, por lo tanto, se halla enormemente sujeta a influencias ideológicas y socioculturales. En ocasiones parece que casi «intrínsecamente sujeta» a esas influencias, a pesar de que todo el método científico es una búsqueda (¿prometeica?) de la «objetividad», del desligamiento de las ataduras del científico y la humanidad como sujetos. Por otro lado, toda investigación, por científica que se postule, es en realidad más o menos tecnológica, es decir tiene que ver con la tecnología —en el sentido de la tablas 8 y 9.

La tecnología, a diferencia de la ciencia, busca elaborar una regla para producir un acontecimiento concreto a partir de unas condiciones definidas. La investigación básica tiene más que vez con el conocer como fin en sí mismo. Pero, como ha defendido Quintanilla (30) y yo mismo (5, $10)$, en realidad toda investigación científica tiene mucho de tecnológica, máxime en el momento actual. Con ello, está sujeta a las urgencias y presiones determinadas por organizaciones, estructuras e ideologías concretas de concretas coyunturas socioculturales y económico-sociales. 
DEBATES

Tabla 1.

COMPONENTES DE LA CALIDAD DE UNA TERAPIA CUALQUIERA

\begin{tabular}{|c|c|c|}
\hline 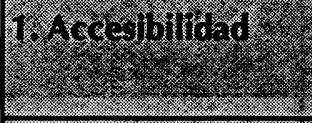 & $8+2$ & $\begin{array}{l}\text { = Facilidad con la cual los consultantes pueden } \\
\text { obtener atención cuando la necesitan. }\end{array}$ \\
\hline 2. Adecuacionis & 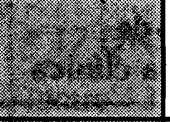 & $\begin{array}{l}\text { = Forma de provisión de un cuidado o terapia, } \\
\text { según el estado del desarrollo tecnológico. }\end{array}$ \\
\hline 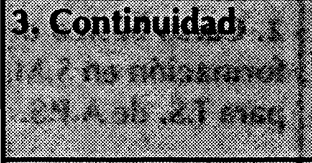 & 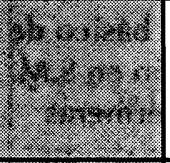 & $\begin{array}{l}\text { = La atención necesaria está coordinada entre } \\
\text { diferentes profesionales, dispositivos, } \\
\text { organizaciones y a lo largo del tiempo. }\end{array}$ \\
\hline 4. Efectividad & & $\begin{array}{l}\text { = Las técnicas o procedimientos se } \\
\text { proporcionan de forma adecuada, según el } \\
\text { desarrollo tecnológico medio («eficacia real»). }\end{array}$ \\
\hline 5, Eficacia 20.2010 & 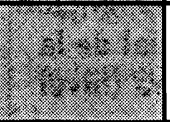 & $\begin{array}{l}\text { = Capacidad de una técnica para solucionar } \\
\text { los problemas para los cuales está indicada. }\end{array}$ \\
\hline 6. Eficiencia & & $\begin{array}{l}\text { = Consumo de esfuerzos, economía, personal, } \\
\text { repercusiones indeseables, etc de una técnica. }\end{array}$ \\
\hline 7. Segurid dad & 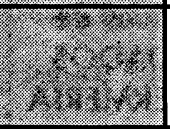 & $\begin{array}{l}\text { = Grado en el cual los procedimientos están } \\
\text { libres de azar o peligros potenciales. }\end{array}$ \\
\hline 8. Oportunidad & 20 & $\begin{array}{l}\text { = Grado en el cual la atención se proporciona } \\
\text { cuando se necesita. }\end{array}$ \\
\hline $\begin{array}{l}\text { 9. Satisfaccion desd } \\
\text { perspectivadelcon } \\
\text { y sus allegados. }\end{array}$ & le la 40.7 & $\begin{array}{l}\text { = Evaluación "objetiva» y mediante entrevista de } \\
\text { la satisfacción de los mismos. }\end{array}$ \\
\hline $\begin{array}{l}\text { 10. Mejora en la cal } \\
\text { vida. }\end{array}$ & & $\begin{array}{l}\text { = Variación en la calidad de vida, evaluada } \\
\text { según los sistemas habituales, entre el «antes» y } \\
\text { el «después» (o «durante») de una terapia. }\end{array}$ \\
\hline $\begin{array}{l}\text { 11: Balance auton } \\
\text { heteronomia. }\end{array}$ & & $\begin{array}{l}\text { = Grado de incorporación de los pacientes y sus } \\
\text { sus familias en los procesos de decisión de la } \\
\text { técnica y en los procesos y procedimientos } \\
\text { exploratorios y terapéuticos. }\end{array}$ \\
\hline
\end{tabular}




\section{Tabla 2.EL PROGRAMA PRIORIZADO DE FORMACIÓN CONTINUADA EN SALUD MENTAL PARA LA ATENCIÓN PRIMARIA DE SALUD DE CATALUNYA}

\begin{tabular}{|c|c|c|c|}
\hline 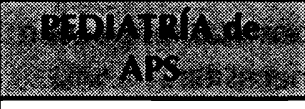 & 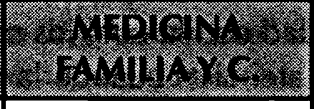 & 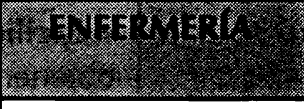 & 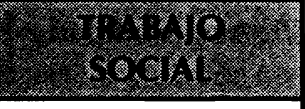 \\
\hline $\begin{array}{l}\text { 1. Curso de } \\
\text { entrevista clínica }\end{array}$ & $\begin{array}{l}\text { 1. Curso de } \\
\text { entrevista clínica }\end{array}$ & $\begin{array}{l}\text { 1. Curso de } \\
\text { entrevista clínica }\end{array}$ & $\begin{array}{l}\text { 1. Curso de } \\
\text { entrevista clínica }\end{array}$ \\
\hline $\begin{array}{l}\text { 2. Curso básico de } \\
\text { formación en S.M. } \\
\text { para A.P.S. }\end{array}$ & $\begin{array}{l}\text { 2. Curso básico de } \\
\text { formación en S.M. } \\
\text { para A.P.S. }\end{array}$ & $\begin{array}{l}\text { 2. Curso básico de } \\
\text { formación en S.M. } \\
\text { para enfermeras } \\
\text { de A.P.S. } \\
\text { (Intervención } \\
\text { psicosocial I) }\end{array}$ & $\begin{array}{l}\text { 2. Curso básico de } \\
\text { formación en S.M. } \\
\text { para T.S. de A.P.S. }\end{array}$ \\
\hline $\begin{array}{l}\text { 3. Introducción } \\
\text { a la atención a la } \\
\text { FAMILIA desde } \\
\text { la A.P.S. }\end{array}$ & $\begin{array}{l}\text { 3. Introducción } \\
\text { a la atención a la } \\
\text { FAMILIA desde } \\
\text { la A.P.S. }\end{array}$ & $\begin{array}{l}\text { 3. La intervención } \\
\text { psicosocial de la } \\
\text { enfermera (nivel } \\
\text { II) }\end{array}$ & $\begin{array}{l}\text { 3. La intervención } \\
\text { del T.S. con grupos } \\
\text { específicos de } \\
\text { consultantes. }\end{array}$ \\
\hline $\begin{array}{l}\text { 4. Introducción a } \\
\text { los PROGRAMAS } \\
\text { PREVENTIVOS } \\
\text { para pediatría } \\
\text { de A.P.S. }\end{array}$ & $\begin{array}{l}\text { 4. Abordaje del } \\
\text { DUELO Y LAS } \\
\text { PÉRDIDAS }\end{array}$ & $\begin{array}{l}\text { 4. Aspectos } \\
\text { psicológicos de } \\
\text { los CUIDADOS } \\
\text { DE ENFERMERÍA }\end{array}$ & $\begin{array}{l}\text { 4. Técnicas } \\
\text { grupales para } \\
\text { T.S. de A.P.S. }\end{array}$ \\
\hline $\begin{array}{l}\text { 5. Grupos de } \\
\text { Reflexión (tipo } \\
\text { BALINT) ó } \\
\text { Seminarios de } \\
\text { Antropología } \\
\text { básica }\end{array}$ & \begin{tabular}{|l|} 
5. Grupos de \\
Reflexión (tipo \\
BALINT) ó \\
Detección y \\
tratamiento precoz \\
de la DEPRESIÓN
\end{tabular} & $\begin{array}{l}\text { 5. Grupos de } \\
\text { Reflexión (tipo } \\
\text { BALINT) }\end{array}$ & $\begin{array}{l}\text { 5. Grupos de } \\
\text { Reflexión (tipo } \\
\text { BALiNT) }\end{array}$ \\
\hline
\end{tabular}

(Derivada del Documento Final del Grupo de Trabajo sobre «Formación Continuada en Salud Mental para la A.P.S. „ del Programa de Salut Mental (Servei Catalá de la Salut), coordinado por el autor, 1996). 
Tabla 3. FARMACOEPIDEMIOLOGÍA Y FARMACOECONOMÍA DE ALGUNOS PSICOFÁRMACOS

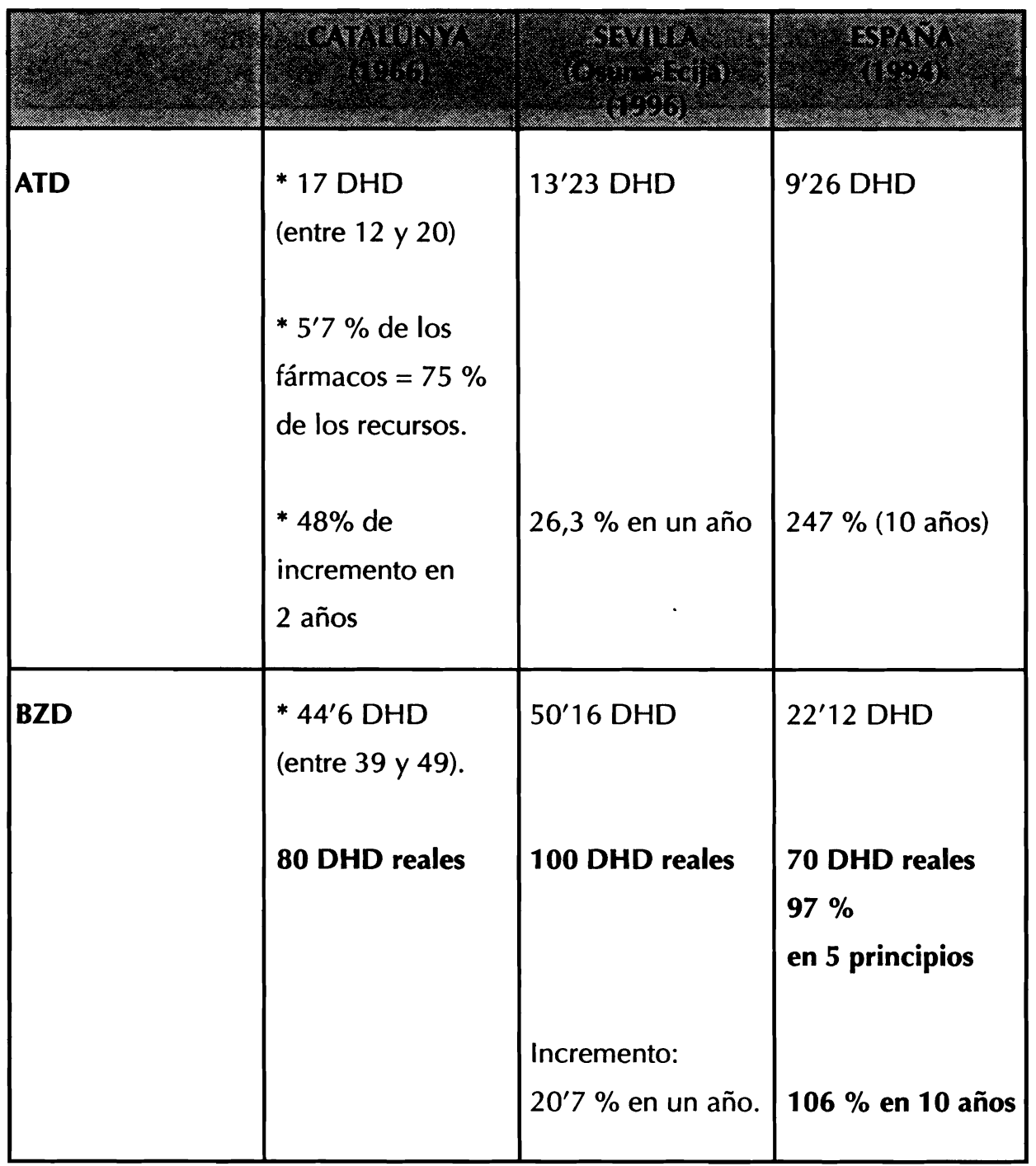

Consumen Psicofármacos de forma habitual:

Al menos $2-3$ \% de la población 


\section{Tabla 4. DOS PERSPECTIVAS DE LA INVESTIGACIÓN (y la Docencia) EN NUESTRA COYUNTURA sociocultural (I)}

\begin{tabular}{|c|c|}
\hline 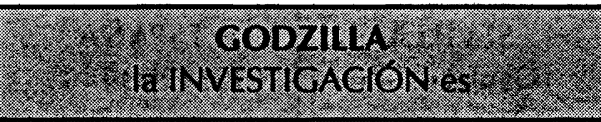 & 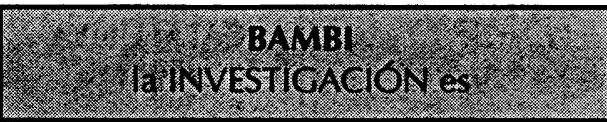 \\
\hline Básica & $\begin{array}{l}\text { Investigación clínica y } \\
\text {. reflexión sobre la clínica. }\end{array}$ \\
\hline Científica & $\begin{array}{l}\text {. Aplicada, no de conceptos, Teorías y } \\
\text { modelos básicos. } \\
\text {. Tampoco investigación tecnológica }\end{array}$ \\
\hline Biológica & $\begin{array}{l}\text { Psicológica } \\
\text {. Particularizada (??) } \\
\text {. de lo individual o de grupos sin } \\
\text { control o comparación. } \\
\text {. pocas veces psicosocial, } \\
\text { asistencial, sociológica... }\end{array}$ \\
\hline $\begin{array}{l}\text { Reduccionista, } \\
\text { casi nunca bio-psico-social }\end{array}$ & $\begin{array}{l}\text {. En contadas ocasiones se investiga la } \\
\text { combinación de tratamientos } \\
\text { (agorafobia, tr. obsesivos...) }\end{array}$ \\
\hline $\begin{array}{l}\text { Metodología } \\
\text { Epistemología empirista }\end{array}$ & $\begin{array}{l}\text { Reflexión } \\
\text { Ept. hermenéutica, dadaísta, } \\
\text { del sentido común, ingenua... }\end{array}$ \\
\hline Solipsista, mecanicista... & Constructivista, construccionista...? \\
\hline
\end{tabular}


DEBATES

Tabla 5. DOS PERSPECTIVAS DE LA INVESTIGACIÓN (y la Docencia) EN NUESTRA COYUNTURA sociocultural

\begin{tabular}{|c|c|}
\hline $\begin{array}{l}\text { GODZILLA } \\
\text { la IMVESTIGACION Es } \\
\end{array}$ & B. BAMBI \\
\hline $\begin{array}{l}\text { * Imperial y de los Centros } \\
\text { Dependientes del Imperio finisecular. }\end{array}$ & $\begin{array}{l}\text { * De grupos e indivíduos aislados, } \\
\text { heroicos, solitarios, no integrados... }\end{array}$ \\
\hline $\begin{array}{l}\text { * La Imperial, } \\
\text { tanto investigación científica } \\
\text { como tecnológica }\end{array}$ & $\begin{array}{l}\text { * «Distracciones», papeles } \\
\text { secundarios, seguidismo...? }\end{array}$ \\
\hline * de la Eficacia & * de lo humano, la hermenéutica... \\
\hline $\begin{array}{l}\text { * propia de «las Instituciones» } \\
\text { (= las grandes instituciones y } \\
\text { las instituciones «totales»). }\end{array}$ & $\begin{array}{l}\text { * propia de las «mentes pensantes y } \\
\text { ensibles, más allá de la ciencia, } \\
\text { antiprotocolos" }\end{array}$ \\
\hline $\begin{array}{l}\text { * lo que publican las «Revistas de } \\
\text { Prestigio internacional» }\end{array}$ & $\begin{array}{l}\text { * desprecio de la publicación en esas } \\
\text { Revistas y sistemas «protocolizados» }\end{array}$ \\
\hline
\end{tabular}


Tabla 6.

OTRA PERSPECTIVA, tal vez menos sectaria, DE LA INVESTIGACIÓN (y la Docencia) EN NUESTRA COYUNTURA sociocultural

\begin{tabular}{|c|c|}
\hline $\begin{array}{l}\text { Ta investicaciones } \\
\end{array}$ & (1) INVESTICACION putede ser: \\
\hline Básica & $\begin{array}{l}\text { Pero también APLICADA } \\
\text { y de la PRAGMÁTICA. }\end{array}$ \\
\hline Científica & $\begin{array}{l}\text { Pero también en la Investigación «básica» } \\
\text { pesan: } \\
\text {. La Ideología: el affair Burt } \\
\text {. La INVESTIGACIÓN TÉCNICA } \\
\text { Y TECNOLÓGICA. }\end{array}$ \\
\hline $\begin{array}{l}\text { Acumulativa y } \\
\text { reductora del desconocimiento }\end{array}$ & $\begin{array}{l}\text {. Contra el desconocimiento y los } \\
\text { dogmas (=seudoconocimientos). } \\
\text {. Con «revoluciones científicas» }\end{array}$ \\
\hline Biológica & $\begin{array}{l}\text {. Psicológico-clínica } \\
\text {. Psicosociológica } \\
\text {. Asistencial, es decir, socioeconómica. }\end{array}$ \\
\hline Reduccionista & $\begin{array}{l}\text { BIO-PSICO-SOCIAL } \\
\text {. Emergentista. } \\
\text {. Constructivista }\end{array}$ \\
\hline Metodología & $\begin{array}{l}\text {. Hay diversos modos de investigación } \\
\text { y diversas metodologías científicas. }\end{array}$ \\
\hline Estadística & $\begin{array}{l}\text {.Estadístico-correlacional, observacional, } \\
\text { experimental, simulativa?... }\end{array}$ \\
\hline Epistemología empirista & $\begin{array}{l}\text {. Inv. Tecnológica con metodología científica } \\
\text { y Ept. del realismo no representativo, } \\
\text { constructivista, construccionista... }\end{array}$ \\
\hline $\begin{array}{l}\text { Orientada hacia la Verdad, } \\
\text { La Realidad }\end{array}$ & $\begin{array}{l}\text {. La REALIDAD como METÁFORA se } \\
\text { construye RELACIONAL Y CONTEXTUALMENTE: } \\
\text {. Principio de Indeterminación } \\
\text {. Efecto Rosenthal } \\
\text {. Efecto UTA }\end{array}$ \\
\hline
\end{tabular}


DEBATES

Tabla 7.

OTRA PERSPECTIVA, tal vez menos sectaria, DE LA INVESTIGACIÓN (y la Docencia)

EN NUESTRA COYUNTURA sociocultural (II)

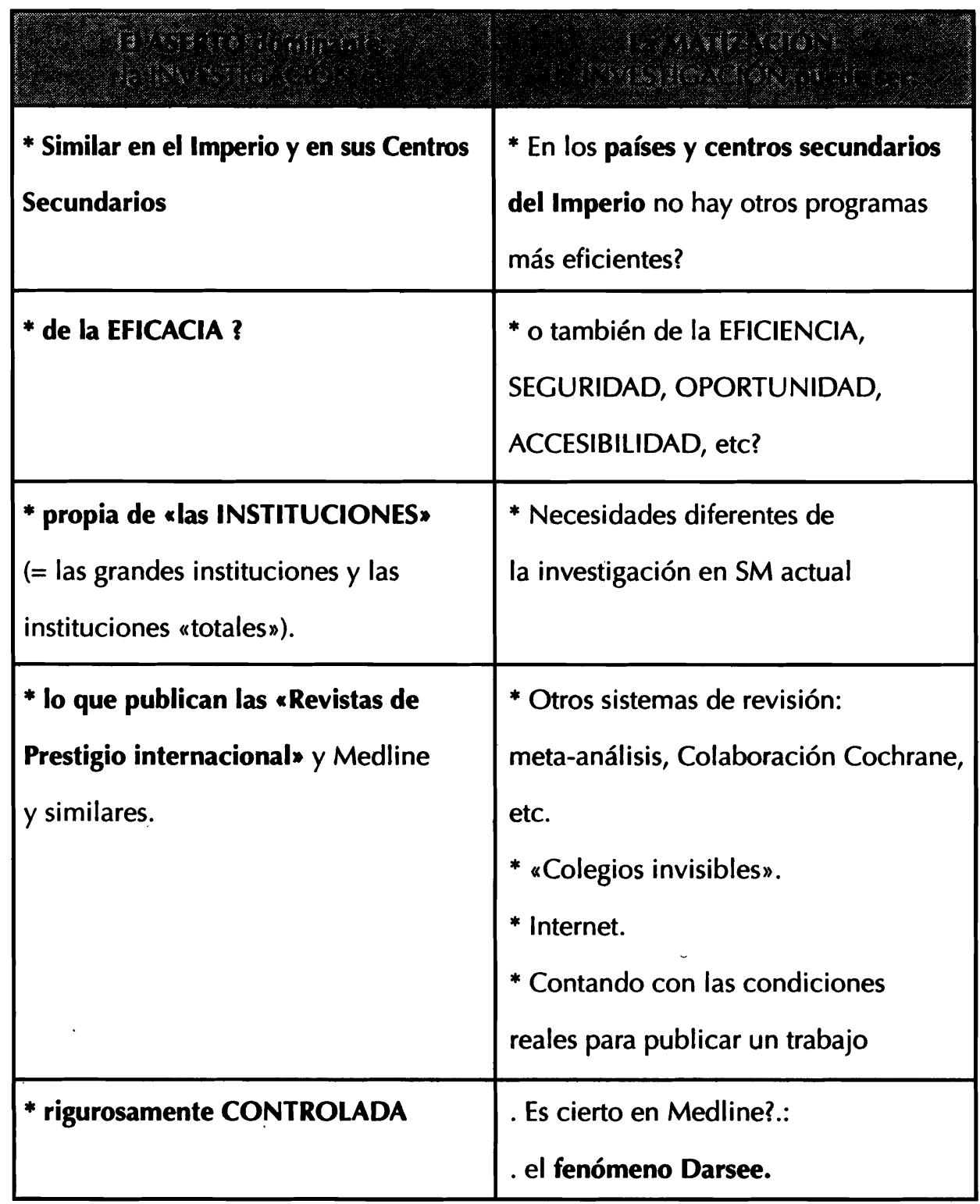


Tabla 8.

DIFERENCIAS FORMALES Y EPISTEMOLOGICAS

ENTRE CIENCIA Y TECNOLOGÍA

(modificada de Quintanilla, 1978, 1981 y Tizón 1995)

\begin{tabular}{|c|c|c|c|}
\hline & & 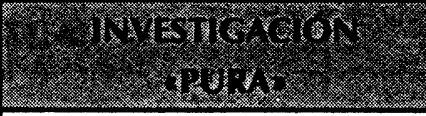 & 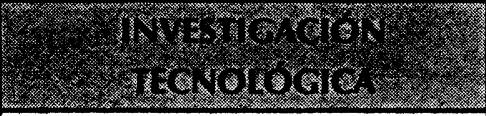 \\
\hline $\begin{array}{l}\text { Punto de } \\
\text { partida }\end{array}$ & $\begin{array}{l}\text { A } \\
\text { C }\end{array}$ & $\begin{array}{l}\text { Acontecimiento } \\
\text { a explicar } \\
\text { Condiciones en las que } \\
\text { se produce } \mathbf{A} \text {. }\end{array}$ & $\begin{array}{l}\text { Resultado } \\
\text { a producir } \\
\text { Condiciones en las que } \\
\text { conviene producir A }\end{array}$ \\
\hline Objetivo & $\mathbf{L}$ & $\begin{array}{l}\text { Ley o teoría que explique } \\
\text { la dependencia de } \mathbf{A} \\
\text { respecto de } \mathbf{C}\end{array}$ & $\begin{array}{l}\text { LEY que permita elaborar } \\
\text { una REGLA para producir } \\
\text { A a partir de C }\end{array}$ \\
\hline
\end{tabular}

Tabla 9. Investigación científica e investigación tecnológica.

EN REALIDAD TODA INVESTIGACIÓN

$$
\text { = dialéctica entre }
$$

EL CONOCIMIENTO COMO FIN EN SÍ MISMO

versus

EL CONOCER PARA TRANSFORMAR

$y$, por tanto,

1) ENORMEMENTE SUJETA A INFLUENCIAS

IDEOLÓGICAS Y SOCIOCULTURALES

2) SIEMPRE MÁS O MENOS TECNOLÓGICA 


\section{NOTAS}

${ }^{1}$ Comunicación verbal realizada por los respresentates de la administración de la Comunidad de Madrid en la Inaguración de las X Jornadas de la Asoc. Madrileña de Salud Mental (AEN), 11 de junio de 1998.

${ }^{2}$ No olvidemos, sin embargo, que los mayores «agujeros financieros» producidos en los últimos decenios en nuestro país, han sido producidos por la «iniciativa privada». Y que entonces, la solidaridad de los medios e instituciones públicas si se ha invocado, se ha puesto en marcha y ha tenido que aplicarse con consecuencias políticas graves $\mathrm{y}$, a menudo, paradógicas: algunos malos administradores han usado y abusado durante años, gracias a las ayudas públicas recibidas, de una gran popularidad mediática y social.

${ }^{3}$ Etimológicamente, clínico y clínica vienen de lecho y, por lo tanto, de «estar junto al lecho», en la cabera de los pacientes o consultantes.

${ }^{4}$ Pues la realidad clínica y social es tozuda e investigaciones independientes como las de la Fundación Cochrane no dejan en buen lugar la pretendida eficacia y eficiencia del «managed care».

${ }^{5}$ Con una demanda que, en el caso de la Unidad de Salud Mental de Sant Martí Nord (Barcelona), en la que trabajo, sigue superando una incidencia en servicio anual del uno por ciento de la población desde hace más de dieciséis años.

${ }^{6}$ En este sentido recuerdo a menudo que, si bien las técnicas de auscultación, radiológicas, de laboratorio, de imagen computerizada, etc. son básicas en la asistencia médica y los médicos deben formarse adecuadamente en ellas, niguna de las mismas es usada en más del 20 a 30 por ciento de las entrevistas o visitas... Por el contrario, la entrevista clínica y sus técnicas (o la carencia de ellas) es usada ... ien el 100 por cien de las entrevistas, naturalmente!

${ }^{7}$ Aunque vengo nombrándolas así desde hace años, como ustedes saben, en 1997 Hoolywood ha hecho tan popular a Godzilla que, tal vez, convendría cambiar el nombre de la segunda de ellas. Antes, Godzilla era un simple monstruo de films japoneses de serie B y C, sobre el cual se llegaron a realizar decenas del filmes. Un gran monstruo procedente de la prehistoria que, como tal vez King-Kong, posee atributos humanos: ternura, sentido del humor, sarcasmo en ocasiones... Y resultaba menos grandioso y apabullante que King-Kong. Por el contrario, «Bambi» podría representar la quintaesencia de la sensibilería de determinada cultura occidental, una forma refinada de utilizar el sadomasoquismo en los mitos y cuentos familiares, y uno de los métodos más eficaces para sujetar a los niños frente al vídeo, durante los últimos 20 o 30 años.

${ }^{8}$ Pero no ocurre lo mismo en las disciplinas psicológicas, psicosociales y sociológicas de las «ciencias y técnicas de la salud mental»: la investigación básica resulta a menudo desdeñada o pospuesta por intereses inmediatistas y pragmáticos. $\mathrm{O}$, simplemente, por el desinterés.

${ }^{9}$ ¿Pero cómo, si gran parte de los estudios valorados son bianónimos, aleatorizados controlados?.

${ }^{10}$ Puedo poner hoy aquí un ejemplo procedente de mi propia experiencia personal que radicaliza la complejidad de lo que vengo diciendo: Aunque a algunos les parezca casi un sueño, el franquismo existió. Y una parte de la contestación al mismo, al menos en sus fases tardías, estuvo representada por el movimiento de la reforma psiquiátrica. Las huelgas de Oviedo y la solidaridad con los trabajadores del Hospital Psiquiátrico de Oviedo fué uno de sus momentos álgidos: la solidaridad y las huelgas de solidaridad (por definición «huelgas políticas») se extendieron por el país a través de las huelgas en otras instituciones de salud mental. Aunque no aparezcan muchos datos ni en la «historias oficiales» ni tan siquiera en las historias alternativas, algunos de los que participamos en estas huelgas solidarias, tras ser intimidados de diversas formas por las empresas y las «fuerzas del orden» (se trataba de «huelgas políticas») fuimos despedidos por ello. Más tecnocráticamente, «nuestros contratos no fueron renovados»... En algunos casos, a pesar de las promesas anteriores. Pero no sólo fuimos despedidos 
sino que funcionaba un sistema, que por entonces se llamaba «listas negras», que significaba que cuando uno iba a buscar trabajo era rechazado una y otra vez en virtud de los informes políticos previos acumulados por tales «actividades subversivas». La terquedad y primitivismo de tal sistema represivo fué tal que yo mismo tengo la experiencia de ir a comenzar un nuevo trabajo mañana por la mañana y por la noche recibir una intempestiva llamada de mi futuro director ( $y$ amigo) que te dice con voz ronca y entrecortada: «Pues mira, no puedes entrar... Y se que entrabas mañana, pero ...» Esa situación llevó a más de uno a la emigración y a otros nos obligó a trabajar como médicos de cabecera en el INP... y complementariamente, a trabajar como contratados en la industria químico-farmacéutica. Y con ello, como digo a veces con humor negro, Franco, sin saberlo, nos enseñó muchas cosas contra el «pensamiento único», del que él mismo fué un adelantado y primitivo defensor. En mi caso, pasé dos años trabjando en un «departamento de investigación» de una industria químico-farmacéutica nacional asociada con uno de los laboratorios mundiales punteros en la investigación en farmacología del SNC. Mi obligación consistía en seleccionar los trabajos clínicos, farmacológicos y de investigación que me parecían metodológicamente más correctos y recomendar o realizar su traducción o resumen. Es decir: personalmente valoraba, de entre centenares de trabajos internacionales referidos a los principios activos del laboratorio, cuáles iban a utilizarse para la valoración y difusión de los productos. Uno de los productos de tal laboratorio y de sus asociados intenacionales, se mantuvo entre 3 y 5 años como líder de ventas nacional e internacional... Por mis manos pasaron centenares de trabajos clínicos y farmacológicos referidos al mismo. Como el caso de los referidos a otros fármacos, estoy seguro que la mayorfa, si no todos aquellos trabajos, eran metodológicamente correctos... La mayorfa obedecfan a una metodología «bianónima cruzada» o «aleatorizada controlada». Y sin embargo, hoy ese producto ha desaparecido del mercado, no por haber sido superado por otros más modernos, sino porque estudios independientes anteriores y posteriores mostraron su total ineficacia y las bases míticas sobre las que estaba «explicado» su mecanismo de acción. Para mí es una buena muestra de que «hay un fantasma en la máquinan, de que no se trata tan sólo de mala voluntad y prácticas corruptas de los investigadores y las empresas químico-farmacéuticas. Todos tenemos noticia de «ensayos clínicos» cuyos datos y pacientes se fabrican en una

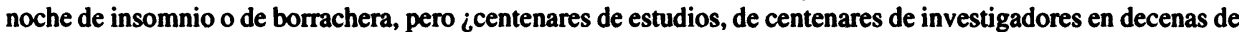
países?. Por eso digo que esa experiencia me hizo «aprender mucho», «gracias a (o a pesar de) Franco»: de ahi viene una parte de mi convicción personal de que existen una serie de sesgos intrínsecos en la situación actual de la ciencia y la tecnología

\title{
BIBLIOGRAFIA
}

las referencias bibliográficas aparecerán en la segunda parte

\author{
* Psiquiatra de Atención Primaria y Psicoanalista. \\ Director de la Unidad de Salud Mental «Sant Martí-Nord» \\ Institut Catalá de la Salut. Barcelona
}

Dirección:

Unitat de Salud Mental de Sant Martí-Nord (I.C.S.)

Plaza de la Infancia, s/n

08020 - Barcelona

Fecha de recepción: 23-VIII-2000 